\title{
Preface: DeAth By InCARCERATION
}

A NATURAl Life Sentence. The other death penalty. Death by incarceration. These are the apt descriptions of life without the possibility of parole (LWOP), the most severe prison sentence possible in the United States. As the name suggests, inmates serving this sentence are ineligible for parole. Other than the vacating of a LWOP sentence by an appellate court, commutation is the only other theoretical means by which a LWOP inmate would be released from prison. However, the likelihood of release either through court order or executive clemency is virtually nonexistent. The most likely outcome for virtually all LWOP inmates is that they will die in prison.

There are approximately forty-nine thousand federal and state inmates serving life without parole in the United States (Nellis 2013, 1). Of the one and a half million sentenced inmates in this country (Carson and Sabol 2012, 1), about 3.3 percent are serving a LWOP sentence (Nellis 2013, 6). While still a small portion of the overall prison population, the number of LWOP inmates has increased precipitously over the last several decades to the point where there are now roughly the same number of individuals serving life without parole in the United States as the total prison populations of forty-three states (Carson and Sabol 2012,22). Yet despite the severity of the sentence and the growth of the LWOP population, these inmates receive little attention. They are a group that has been forgotten.

Similar to inmates who receive the formal death penalty, LWOP inmates are executed by the State, though the process is much different. Their cases do not receive additional scrutiny from appellate courts to ensure the punishment is fair. Their deaths do not occur on a scheduled day and time after they have had the opportunity to say goodbye to loved ones and consume a specially requested meal. When LWOP inmates die, there are no abolitionists outside the prison protesting the unjustness of the punishment. Their deaths do not attract intense media coverage. Rather, for LWOP inmates, death is much more banal. The "execution," the eventual succumbing to disease, illness, or advanced age, is the culmination of a decades-long process fraught with the uncertainty of not knowing whether they will ever be released from prison 
and if not, when and how they will die in prison. Older inmates can expect to incur casualties, in particular to their social networks and to their physical health, over the course of three decades of confinement, the average length of a life sentence (Mauer et al. 2004, 12). Because of the length of time that LWOP inmates can expect to be incarcerated, it is difficult to maintain connections with the outside world. As their relatives grow old and die, their ties to the outside become increasingly splintered. Older LWOP inmates, themselves, are not immune to the aging process. They can expect to encounter many of the same medical conditions that older people face, yet they are in an environment in which they have little control over the quality of the medical care they receive. After struggling to carve out a life that is personally meaningful, and surviving a predatory prison environment, almost all can expect their deaths to occur in prison and without loved ones nearby. Death by incarceration.

The contention that "death is different" has led to greater oversight of death penalty cases (for an extensive discussion see Henry 2012). While the processes differ considerably, the ultimate outcome of the death penalty or death by incarceration is the same. This position is reflected in the following statement from Noah, who was sixty-three years of age and had spent almost half of his life serving life without parole (see Appendix A for more information about pseudonyms): "It dawns on you that, man, you know what? Man, you've got the death penalty. Really, you got the death penalty. [It's] not that you have a set date . . . but there's a slow death penalty because, see, you are sentenced to natural life that means until the rest of your life. And when it starts seeping in . . chances are I'm going to die here."

Both sentences constitute a rejection by the public, as they send the message that the offenders are unworthy of ever reentering society, either because of the severity of the offense or because of their perceived dangerousness. Yet, given the comparative size of the populations and the number of offenses punishable by each, death by incarceration has a far wider reach than the formal death penalty. The LWOP population dwarfs the death-sentenced population, forty-nine thousand versus thirty-one hundred (Snell 2013, 1). Moreover, there are more offenses (e.g., rape) and types of offenders (e.g., habitual property offenders) eligible to receive life without parole than the death penalty.

Despite the size of the population, the heterogeneity of LWOP-eligible offenses and offenders, and the low likelihood of release, researchers have devoted little time to examining the offenders' correctional experiences, and correctional administrators have been remiss in developing prison programming to address their needs. Therefore, the purpose of this book is to give voice to twenty-five older men who are serving LWOP sentences. Based on in-depth interviews conducted in the fall of 2006 and in the fall of 2011, The Forgotten Men provides unprecedented access into the lives of men who 
are serving the most severe prison sentence imaginable. In 2011 all of the men were at least fifty-five years of age and had been incarcerated for at least twenty years, though half of them had been incarcerated in excess of thirty years.

While this book centers on the experiences of a small group of older long-term inmates, their collective story can be seen in a broader context. First, these inmates are survivors of a life spent confined. For this reason alone, their lives arouse curiosity. What kind of lives have they created for themselves? How have they coped with permanent confinement? Listening to their accounts of life in a sparse and often violent world provides insight into the resiliency of the mind and spirit. These men serve as proof that the psyche can withstand a variety of stresses and losses. Second, these men are aging under special circumstances in controlled facilities that were not designed for them. As will be discussed more fully, their biological ages and how old they feel vary widely from their actual chronological ages. Most men reported that they felt younger, and in some cases decades younger, than their actual ages. Due to the monotony of prison life, they claim that prison has preserved them. At the same time, they experience medical problems similar to those of older people residing in free society. Almost all have at least one physical health condition, though comorbidity is common. In contrast to the decline in physical health, most believe that their mental health has improved over the course of confinement. They claim that maturation has made them self-aware, patient, and less impulsive. Because of their self-growth, combined with the length of time they have been incarcerated and their low likelihood of recidivating, the men feel as though they should be permitted to reenter society. However, release is highly improbable and dying in prison is the reality for most of the permanently incarcerated. In the five-year interim period between interviews, three men died (Thomas, Anthony, and Samuel), and Walter has died since the second interview.

While the population and the conditions of confinement are unusual, there are themes present in the men's accounts that are universal-including adaptation, survival, finding meaning in life, redemption, and hope. Finding purpose in life is a commonly held desire by most people, including the men featured in this book. Over the two decades they have been incarcerated, they have struggled to find meaning in their lives. Most have made efforts to better themselves (through education, for example) and have positively contributed to the prison through their advocacy, mentorship, and service to other inmates

This book also raises important questions regarding the meaning of life. What is the value of a life spent incarcerated? Hope of release is fundamental in many of the men's belief systems. They have never relinquished the hope that they will one day be freed. This hope of release, however remote, profoundly shapes their behavior. They work to make themselves as attractive 
for release as possible by avoiding trouble and seeking out opportunities for self-improvement. They protect their physical health by exercising and monitoring their diets so they could have active lives in society should they be released. For some, their lives revolve around their pursuit of release. This glimpse behind the walls forces us to contemplate not only the meaning of life but the human costs of punishment.

Chapter 1 traces the history of life without parole and frames the major arguments in the LWOP debate. The men featured in this book are introduced in Chapter 2, and a typology of their different offenses and other biographical information are presented. Chapter 3 examines the pains of permanent imprisonment, most notably the separation from loved ones, institutional thoughtlessness, and the indeterminacy of the sentence. The coping strategies employed by the men to manage a LWOP sentence are presented in Chapter 4. In Chapter 5, the physical and mental health of the men and the two possible forms of release from a LWOP sentence-sentence modification and death, with the latter being the most likely outcome-are examined. The final chapter presents policy recommendations and calls for a reexamination of the current use of life without parole in the United States. 